\title{
ERBIUM-DOPED SILICON NANOCRYSTALS GROWN BY R.F. SPUTTERING METHOD: COMPETITION BETWEEN OXYGEN AND SILICON TO GET ERBIUM
}

\author{
M. F. Cerqueira ${ }^{a}$, M. Stepikhova ${ }^{b}$, M. Losurdo ${ }^{c}$, M.M. Giangregorio ${ }^{c}$, A. Kozanecki ${ }^{\text {d }}$, T. \\ Monteiro
}

\begin{abstract}
${ }^{a}$ Departamento de Física, Universidade do Minho, Campus de Gualtar 4710-057 Braga, Portugal, 'Institute for Physics of microstructures, RAS, 603600 Nizhnij Novgorod, GPS-105, Russia, ${ }^{c}$ Institute of Inorganic Methodologies and Plasmas, IMIP-CNR, and INSTM, Via Orabona 4- Bari, Italy,

${ }^{\mathrm{d}}$ Polish Academy of Sciences, Institute of Physics, PL-02668, Warsaw,

${ }^{\mathrm{e}}$ Departamento de Física, Universidade de Aveiro, Campus de Santiago, 3700 Aveiro, Portugal
\end{abstract}

\begin{abstract}
Erbium doped micro- and nanocrystalline silicon thin films have been deposited by co-sputtering of Er and Si. Films with different crystallinity, crystallite size, hydrogen and oxygen content have been obtained in order to investigate the effect of the microstructure and composition of matrix on the near IR range at $1.54 \mu \mathrm{m}$ Er-related photoluminescence (PL) properties. The correlation between the optical properties and microstructural parameters of the films is investigated using spectroscopic ellipsometry. It is found that the luminescent properties of these composite films can be understood on the basis of the ellipsometric analysis that reveals the films heterogeneous structure, and that Er-related PL dominates in films with 1-3 nm sized Si nanocrystals embedded in a-Si:H.
\end{abstract}

Keywords: nc-Si, erbium-doping, spectroscopic ellipsometry, optical properties, thin films.

\section{Introduction}

Efficient light emission at room temperature from silicon-based materials for optoelectronic integration is one of the main issues in current materials research. Introduction of $\mathrm{Er}^{3+}$ ions into a $\mathrm{Si}$ network takes special significance for the optical communication systems due to the emission line at $1.54 \mu \mathrm{m}$ (that originates by the intra-4f transitions of $\mathrm{Er}^{3+}$ ions) [1].

So far, materials that have been intensively investigated are $\mathrm{SiO}_{2}: \mathrm{Er}$, a-Si:H,O,Er and c-Si:Er, this last being affected by a strong thermal quenching of the Er photoluminescence (PL). Recently, nc-Si:Er and $\mu \mathrm{c}-\mathrm{Si}$ :Er has been investigated. The idea is based on the band-gap widening of nanometer sized $\mathrm{Si}$, which results in a reduction of the thermal quenching of Er-related luminescence. Indeed, evidences 
have been reported that Er-doped nc-Si thin films have enhanced intra-ionic luminescence and reduced thermal quenching with respect to the crystalline Si [2-5]. Moreover, controversial results have been obtained for the Er related radiative lifetime and quenching mechanisms, as pointed in ref [6].

In the present contribution, the influence of the complex film nanostructure, i.e. the crystallites volume fraction and size, and the doping content (mainly erbium, hydrogen and oxygen), on the $\mathrm{Er}^{3+}$ photoluminescence properties is investigated. The peculiarity of this study is the use of spectroscopic ellipsometry (SE) to elucidate the correlations between the PL efficiency and the silicon matrix. The films of nanocrystalline (nc-) and microcrystalline ( $\mu \mathrm{c})-\mathrm{Si}: \mathrm{Er}: \mathrm{H}: \mathrm{O}$ have been obtained by co-sputtering of Si and Er in an hydrogen rich atmosphere.

\section{Experimental}

Erbium doped micro- and nanocrystalline silicon thin films were grown by reactive magnetron sputtering on ordinary glass substrates. The target was a c-Si wafer where some pieces of high purity (99.99\%) metallic erbium were added for the Er-doping. All samples were grown in a hydrogen rich atmosphere, $\mathrm{R}_{\mathrm{H}}=0.63\left(\mathrm{R}_{\mathrm{H}}=\mathrm{pH}_{2} /\left(\mathrm{pH}_{2}+\mathrm{pAr}\right)\right.$ represents the hydrogen fraction); oxygen was present at a contamination level during the deposition procedure.

We grew sets of Er-doped silicon thin films that differ by the incorporated amount of oxygen and hydrogen. For each set, samples with different structure (nanocrystallite fraction and size) were deposited by varying the deposition temperature [7]. The different sets have different $\mathrm{O} / \mathrm{H}$ ratio, which has a strong impact on the film microstructure and consequently on the PL properties.

Table I: Growth conditions for Erbium doped nanocrystalline silicon thin films, their atomic content and structural parameters

\begin{tabular}{|c|c|c|c|c|c|c|c|c|}
\hline Sample & $\begin{array}{c}\text { Temperature } \\
\left({ }^{\circ} \mathrm{C}\right)\end{array}$ & $\begin{array}{c}\text { Er } \\
(\text { at\% })\end{array}$ & $\begin{array}{c}\mathrm{Si} \\
(\text { at\% })\end{array}$ & $\begin{array}{c}\mathrm{O} \\
(\text { at\% })\end{array}$ & $\begin{array}{c}\mathrm{H} \\
(\text { at\% })\end{array}$ & $\begin{array}{c}\mathrm{D}_{\mathrm{TEM}} \\
(\mathrm{nm})\end{array}$ & $\begin{array}{c}\mathrm{D}_{\mathrm{R}} \\
(\mathrm{nm})\end{array}$ & $\begin{array}{c}\mathrm{C}_{\mathrm{R}} \\
(\%)\end{array}$ \\
\hline Er34 & 50 & 0.03 & 72.3 & 0 & 27.5 & 3 & 0 & 0 \\
\hline Er51 & 300 & 2.3 & 91 & 0 & 6.7 & - & 0 & 0 \\
\hline Er53 & 200 & 2.4 & 80.6 & 9 & 8 & - & 0 & 0 \\
\hline Er40 & 350 & 1 & 80 & 2 & 17 & - & 6.8 & 69 \\
\hline Er48 & 300 & 3 & 81 & 14 & 3 & - & 6.6 & 39 \\
\hline P11 & 300 & 1.4 & 85.6 & 10 & 3 & - & 7.8 & 55 \\
\hline
\end{tabular}

D - Average crystal size by TEM (transmission electron microscopy) and Raman; $C_{R^{-}}$crystalline volume fraction by Raman

The chemical composition (see Table I) was determined by combining the Rutherford Backscattering Spectroscopy (RBS) and Elastic Recoil Detection (ERD) techniques. Structural characterization of the size and volume fraction of crystallites was carried out by micro-Raman spectroscopy under excitation 
with $514.5 \mathrm{~nm}$ line of $\mathrm{Ar}^{+}$laser. To analyze the Raman spectra, computer simulations were used, considering the spectral profile as a superposition of the amorphous and crystalline parts. The crystalline profile was calculated on the basis of the Strong Phonon Confinement model [8] and a Gaussian profile was attributed to the amorphous TO peak.

Spectroscopic ellipsometry (SE) was also applied to analyze the film structure. SE spectra of the real, $\left\langle\varepsilon_{1}\right\rangle$, and imaginary, $\left\langle\varepsilon_{2}\right\rangle$, parts of the complex pseudo dielectric function, $\langle\varepsilon\rangle=\left\langle\varepsilon_{1}\right\rangle+i\left\langle\varepsilon_{2}\right\rangle=$ $(n+i k)^{2}$ ( $n$ is the refractive index and $k$ is the extinction coefficient) were measured in the $0.75-5.5 \mathrm{eV}$ energy range using a phase modulated spectroscopic ellipsometer (UVISEL- Jobin Yvon) at an angle of incidence of $70.57^{\circ}$. These spectra were analyzed using models based on the Bruggeman effective medium approximation (EMA) [9]. Since spectroscopic ellipsometry distinguishes the optical constants, namely the refractive index and extinction coefficient, of stechiometric, $\mathrm{SiO}_{2}, \mathrm{SiO}$ and substechiometric silicon oxides, this technique was used to determine the composition of the matrix where the crystals are embedded in. To describe the silicon matrix an EMA mixture of the dielectric function of nc-Si [10], $\mu \mathrm{c}-\mathrm{Si}$ [11], a-Si [12], SiO [13] and of voids (this last modelling grain boundaries and microporosity). For the erbium chemical environment, experimentally determined dielectric function of silicide $\mathrm{ErSi}_{2}$ and oxide $\mathrm{Er}_{2} \mathrm{O}_{3}$ were used.

PL measurements in the infrared spectral region were performed with the Brucker 66V Fouriertransform spectrometer. The signal was detected by North-Coast germanium detector; model EO-817, being excited by the $514.5 \mathrm{~nm}$ line of an Ar laser. The samples were placed on the cold finger of a continuous-flow liquid $\mathrm{He}$ cryostat and studied in the temperature range of $6-300 \mathrm{~K}$.

\section{Results and discussion}

\section{1 - Structural characterization of the Si matrix}

The results of chemical and structural characterizations carried out for the samples produced are presented in Table 1. According to Raman analysis we have indication that a group of samples have an average Si-crystallite size of approximately 6-8 nm, while other samples were basically amorphous. Nevertheless, high resolution TEM performed for one of the basically amorphous silicon samples have shown the presence of small crystallites, with a size distribution peaked at approximately $3.0 \mathrm{~nm}$. Since the larger average silicon crystallite size, D, of the former samples, thereafter we denote them as microcrystalline samples $(\mu \mathrm{c}-\mathrm{Si}$ ) (with $\mathrm{D}>6 \mathrm{~nm}$ ) to distinguish them from the others samples named nanocrystalline samples (nc-Si) (with D $3 \mathrm{~nm}$ ). 
As for film composition, RBS results indicate that samples differ in the hydrogen and oxygen contents, i.e., the $\mathrm{O} / \mathrm{H}$ ratio. Therefore, we discuss samples with nano- (Er34 and Er51) and micro-crystallites (Er40) embedded in an a-Si:H matrix and with nano- (Er53) and micro-crystallites (Er48, P11) embedded in hydrogenated $\mathrm{SiO}_{\text {x. }}$ The erbium content in the samples varies in the range from 0.03 at\% (for Er34) to 3 at\% (for Er48), with a chemical bonding that depends on the matrix composition and nanostructure.

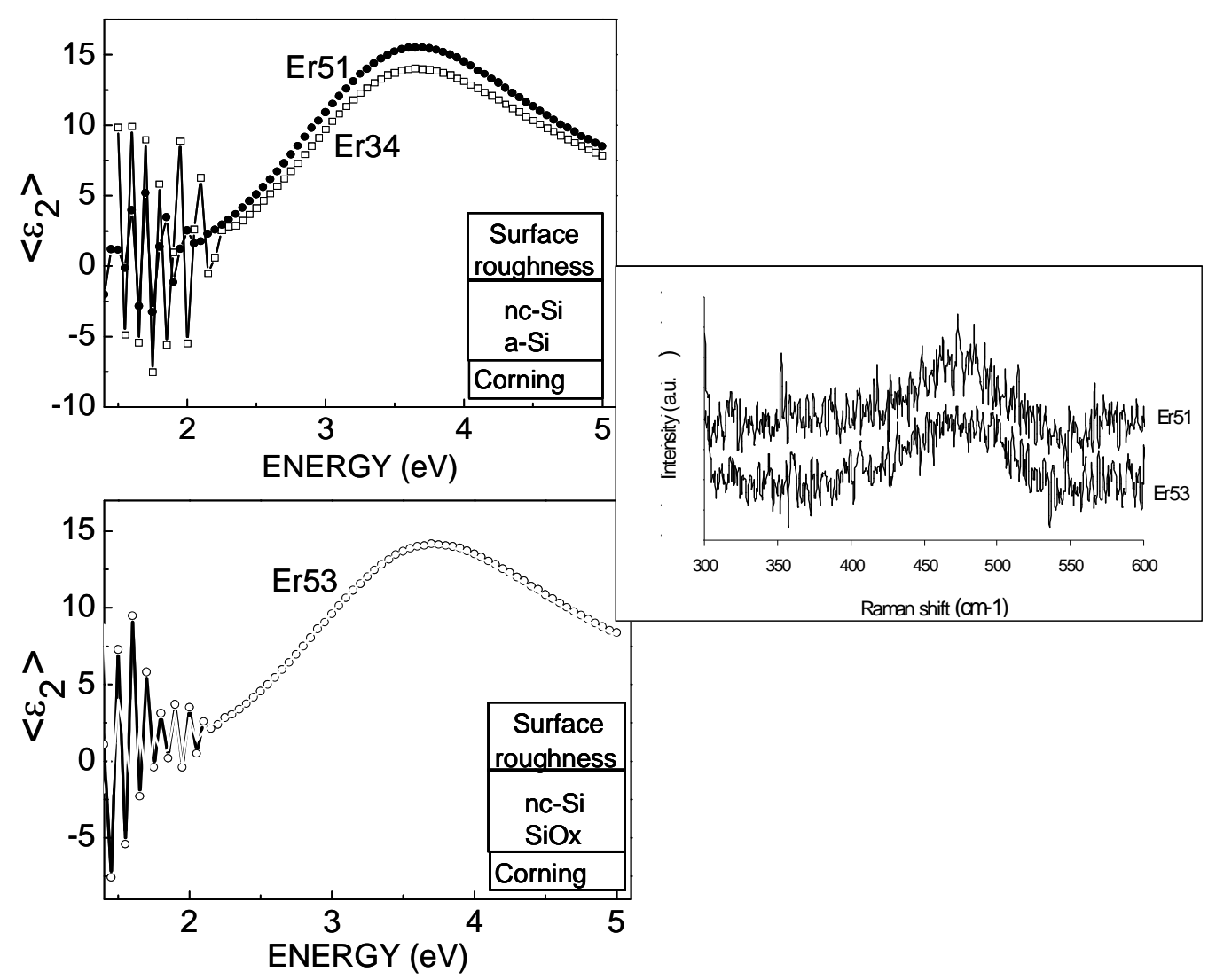

Figure 1 - Raman spectra and SE spectra of the imaginary part, $\left\langle\varepsilon_{2}\right\rangle$, of the pseudodielectric function of erbium doped silicon thin films, which show only the amorphous feature by Raman. All those films have Si nanocrystallites (diameter $<3 \mathrm{~nm}$ ) embedded in an amorphous matrix, but the Er51 and Er34 films have nanocrystallites embedded in a-Si:H, while Er53 has nanocrystallites in amorphous silicon oxide according to the models sketched in the inset. Dots and lines refer to experimental spectra.

Figure 1 shows the ellipsometric spectra of the imaginary, $\left\langle\varepsilon_{2}\right\rangle$, part of the pseudodielectric function of films with $\mathrm{Si}$ nanocrystallites embedded in a-Si:H or $\mathrm{SiO}_{x}$ and the corresponding Raman spectra. Similarly, figure 2 shows the ellipsometric spectra of the imaginary, $\left\langle\varepsilon_{2}\right\rangle$, part of the pseudodielectric 
function of films with $\mathrm{Si}$ microcrystallites embedded in a-Si:H or $\mathrm{SiO}_{\mathrm{x}}$ and the corresponding Raman spectra. The observed different pseudodielectric response is related to differences in composition and nanostructure. In particular, the $\left\langle\varepsilon_{2}\right\rangle$ spectra in Fig. 1 show a single peak at about $3.6 \mathrm{eV}$ that is a characteristic of amorphous silicon, consistently with the Raman spectra that show mainly the band at $480 \mathrm{~cm}^{-1}$ related to amorphous silicon. Nevertheless, the SE spectra of the samples presented in Fig 1 have indicated that the optical gap of these films exceeds $2 \mathrm{eV}$. This high-gap value could not be explained by the large content of hydrogen into the a-Si network (for a $27 \%$ of hydrogen in a-Si we found an optical gap of $1.87 \mathrm{eV}$ ). The best-fit of SE spectra was obtained only by including in the film structure a volume fraction of $\mathrm{Si}$ nanocrystallites (nc-Si) with a diameter distribution peaked at approximately $3 \mathrm{~nm}$ embedded in a matrix whose composition is controlled by the $\mathrm{O} / \mathrm{H}$ ratio. The presence of these small crystallites (nc-Si) has been also confirmed by the TEM analysis [10]. The difference between samples Er34, Er51 and Er53 in Fig. 1 is the composition of the Si matrix, which the crystallites are embedded in, and which depends on the $\mathrm{O} / \mathrm{H}$ ratio, rather than the crystallites average size. The Er34 and Er51 samples have a large amount of hydrogen and no appreciable oxygen content, as determined by RBS (although a few oxygen at doping level well below the RBS detection limit is present for $\mathrm{Er}^{3+}$ ionization). The corresponding best-fit models that depict the film nanostructure indicate that for those samples the silicon crystallites are embedded in a hydrogenated amorphous a-Si:H matrix (see details in Figure 3a). The best-fit model of the Er53 sample, (shown in figure $3 \mathrm{~b}$ ), with $\mathrm{O} / \mathrm{H}$ ratio $\sim 1$, indicate that the $\mathrm{Si}$ nanocrystallites are embedded in a matrix that could either be a mixture of hydrogenated a-Si and $\mathrm{SiO}$ or a substoichiometric oxide $\mathrm{SiO}_{\mathrm{x}}(\mathrm{x}<1)$.

Conversely, the SE spectra of samples in Fig. 2 show $\mathrm{E}_{1}$ and $\mathrm{E}_{2}$ critical points (CPs) at approximately $3.4 \mathrm{eV}$ and $4.2 \mathrm{eV}$ that are distinctive interband transitions of c-Si (the $\mathrm{E}_{1}$ transition takes place along the $\Lambda$ directions of the Brillouin zone, and $\mathrm{E}_{2}$ represents higher transitions involving the second lowest conduction bands of c-Si) [14]). The presence of the CPs indicates a large crystalline volume fraction consistently with Raman spectra which show a very intense transverse optical (TO) mode around 500 $\mathrm{cm}^{-1}$ related to $\mathrm{c}-\mathrm{Si}$, and larger crystallite size, which from Raman has been estimated approximately 68nm. The best-fit models (see Fig. 3c-d) discern silicon microcrystallites, which are embedded in a$\mathrm{Si}: \mathrm{H}$ or $\mathrm{SiO}_{\mathrm{x}}$ matrix. Although this matrix is modeled as a BEMA mixture of a-Si and $\mathrm{SiO}$, we cannot exclude that it is a substoichiometric $\mathrm{SiO}_{\mathrm{x}}(\mathrm{x}<1)$ phase. Furthermore, from the structural point of view all samples show a layered structure where the amorphous volume fraction increases toward the surface. This amorphization of the outmost layer might be correlated with the ion bombardment under sputtering conditions. From the compositional point of view, samples with crystallites embedded in the 
a-Si:H matrix have a quite homogeneous structure along the film thickness, while for samples with the $\mathrm{SiO}_{\mathrm{x}}$ matrix the amorphization towards the surface accompanies with segregation of oxygen towards the outmost layer, which can be explained by the oxygen diffusion profile, and the lower the crystalline volume fraction, the higher the $\mathrm{SiO}$ volume fraction.
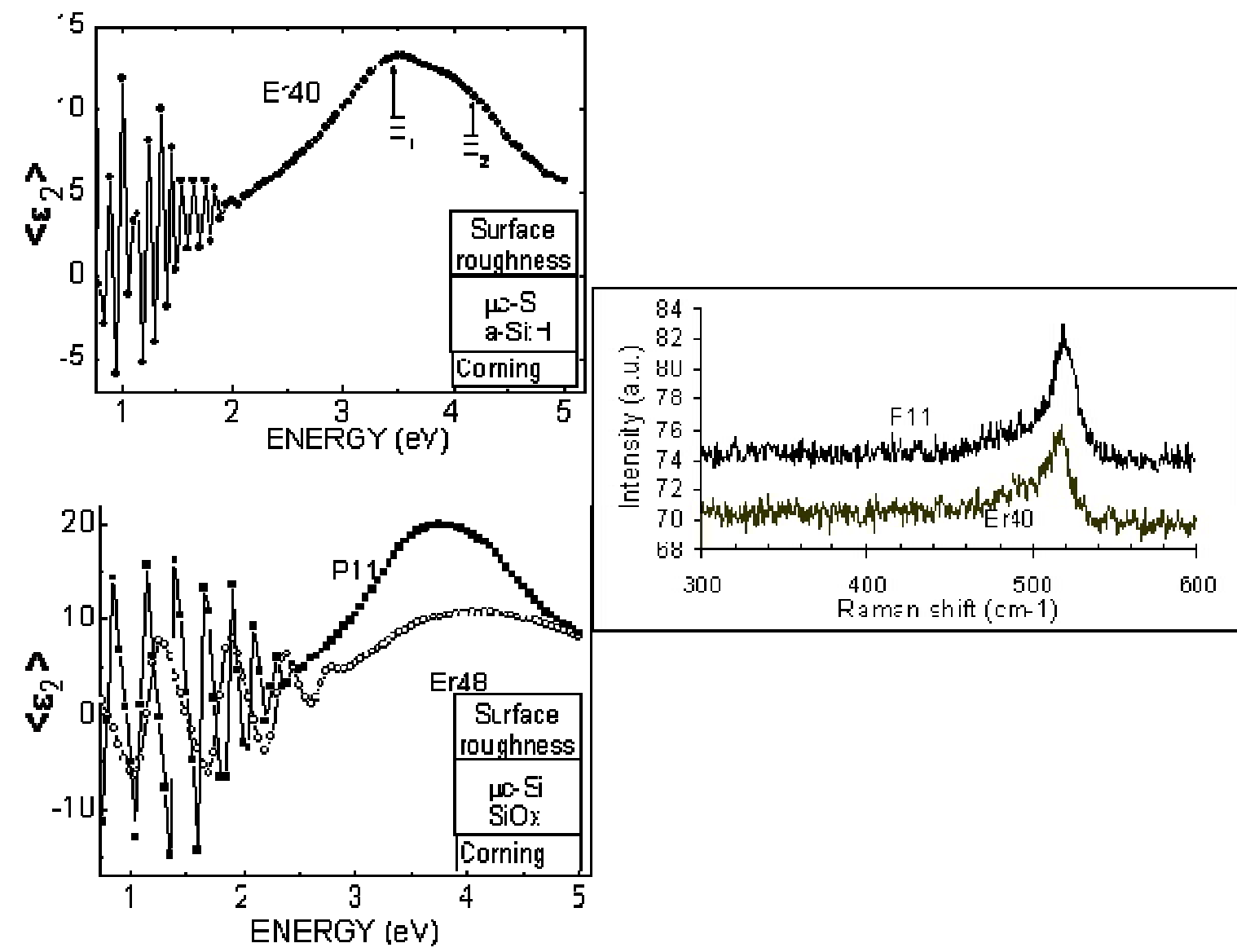

Figure 2 - Raman spectra and SE spectra of the imaginary part, $\left\langle\varepsilon_{2}\right\rangle$, of the pseudodielectric function of erbium doped silicon thin films, which show crystallinity by Raman. All those films have Si crystallites (diameter $>5 \mathrm{~nm}$ ) embedded in an amorphous matrix, but the Er40 film has crystallites embedded in a-Si:H, while Er48 and P11 films have crystallites in amorphous silicon oxide according to the models sketched in the inset. Dots and lines refer to experimental spectra.

As for erbium chemical bonding, SE analysis in fig. 3 indicates that most of erbium can be incorporated into the silicon matrix as silicide $\mathrm{ErSi}_{2}$ or oxide $\mathrm{Er}_{2} \mathrm{O}_{3}$ depending on the composition and nanostructure of the Si matrix. The capability of ellipsometry of being sensitive to the erbium bonding 
is due to the different dielectric response of erbium silicide and erbium oxide shown in Fig. 4. Here, the dielectric function of $\mathrm{ErSi}_{2}$ that also fit our spectra is from ref. 15, while the $\operatorname{Er}_{2} \mathrm{O}_{3}$ dielectric function has been measured experimentally on an oxidized erbium sputtered film. We did not have any evidence of erbium metallic clusters, which could be detected using ellipsometry through its characteristic spectra of the dielectric function.

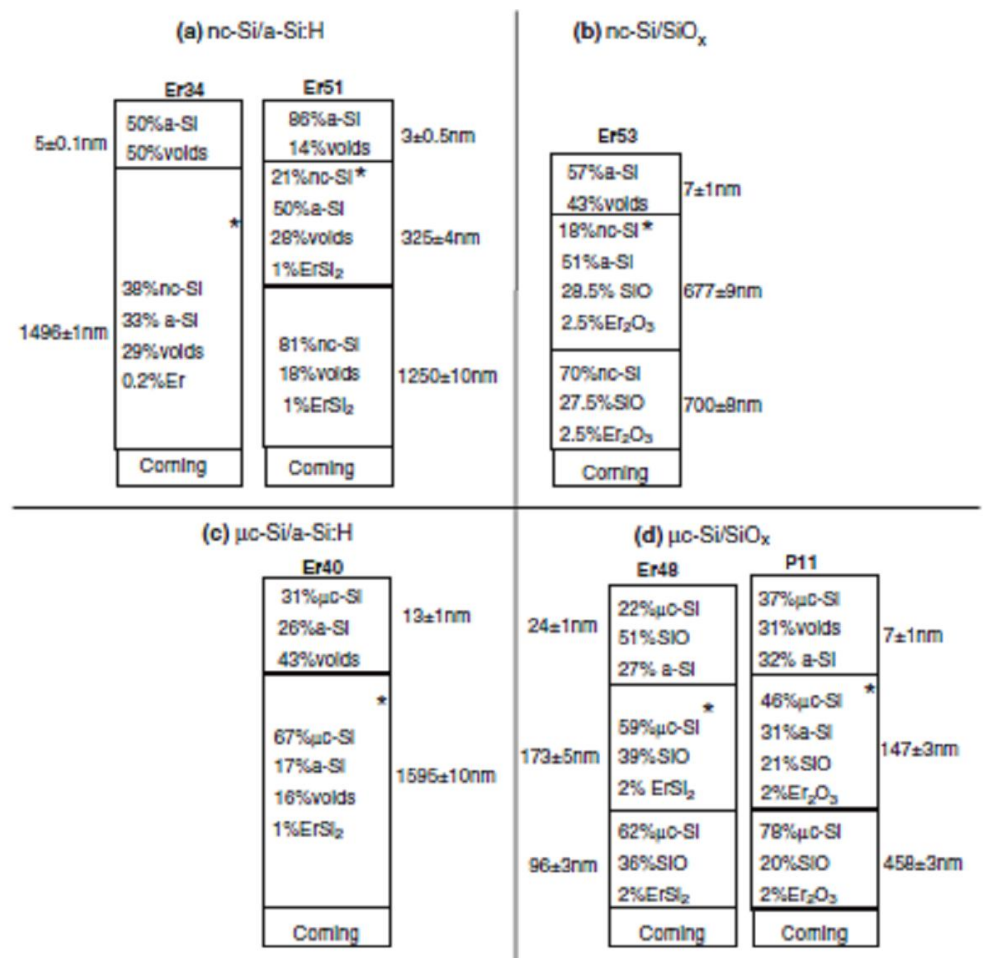

Figure 3 - Best-fit models of SE spectra shown in figures 1 and 2. The symbol (*) indicates the layer probed by the wavelength of laser used for PL measurements.

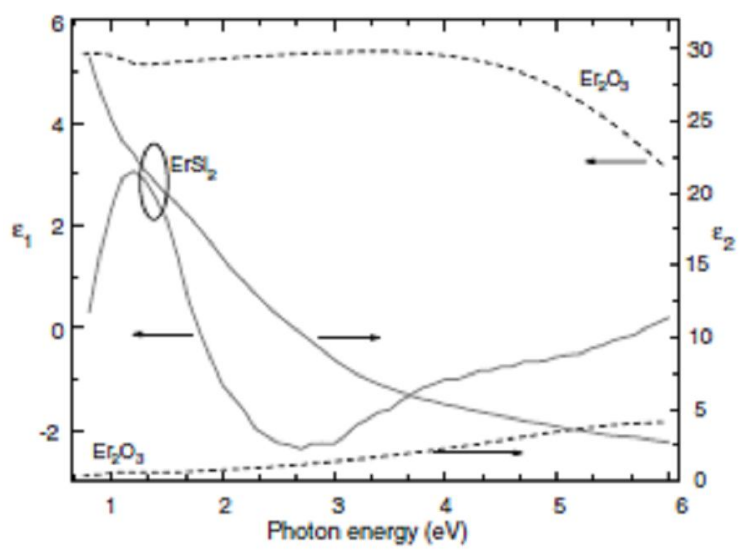

Figure 4 - Spectra of the real, $\varepsilon_{1}$, and imaginary part, $\varepsilon_{2}$, of the dielectric function of $\mathrm{ErSi}_{2}$ (from ref. 15) and of $\mathrm{Er}_{2} \mathrm{O}_{3}$ used in the present analysis of SE spectra. 


\section{2 - Erbium photoluminescence}

As it has been pointed above, the films produced can be grouped into two categories depending on their SE spectra and crystal sizes (nanocrystalline and microcrystalline). Remarkably, these two categories of films have different PL properties, as it can be deduced from the PL data shown in figure 5. All the samples show the PL peak assigned to the intra-4f transition of $\mathrm{Er}^{3+}$ at $1.54 \mu \mathrm{m}$. The PL spectra and the RBS results (table I) indicate that the $\mathrm{Er}^{3+}$ ions fraction involved in the PL is not related to the total amount of incorporated $\operatorname{Er}$ (see for example the erbium content in the Er34 and Er51 samples in Table I), and that a small fraction of the total Er incorporated in the matrix is active for PL (<0.03at\% according to the Er34 sample). Therefore, the different observed PL intensity has been correlated with the silicon matrix. It is found that PL is more intense for the samples with nanocrystallites embedded in a-Si:H (Er34 and Er51) and strongly decreases for the samples with well pronounced $E_{1}$ and $E_{2}$ critical points (see Fig. 2) with larger crystallite size, indicating that the $1.54 \mu \mathrm{m}$ Er-related PL reduces with the increase of silicon crystallite sizes. Furthermore, comparing samples with the same crystallite size and matrix, it is found that the higher the crystallite volume fraction, the higher the PL intensity, indicating that nanocrystallites act as efficient sensitizers for $\mathrm{Er}^{3+}$ excitation.

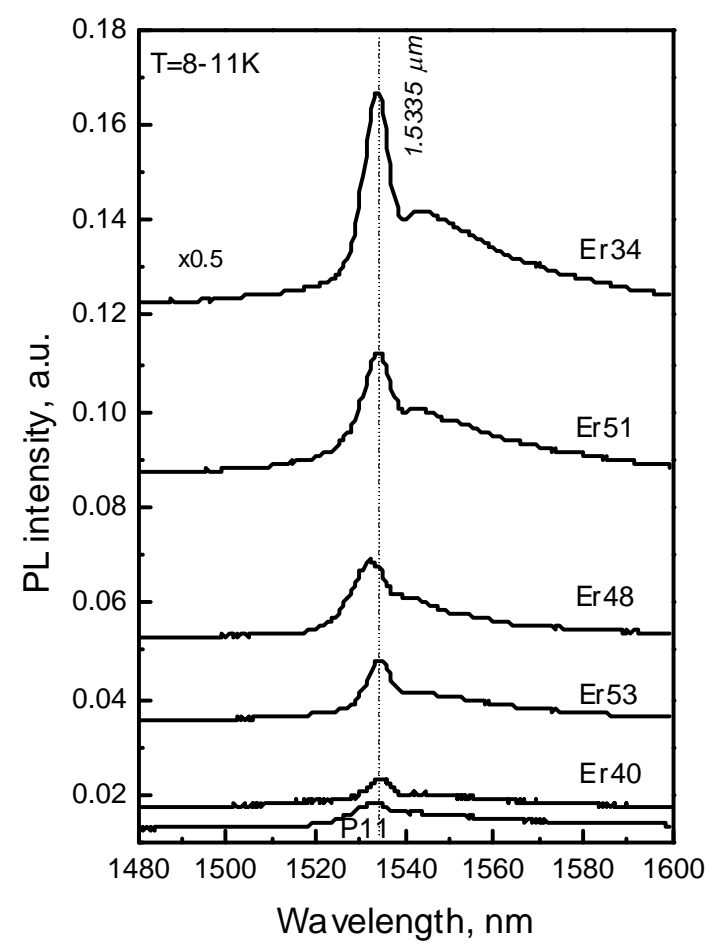

Figure 5 - IR PL spectra for the studied samples, obtained under $514.5 \mathrm{~nm}$ laser line excitation. 
Furthermore, the composition and structure of the matrix where crystallites are embedded in can also affect PL intensity because it can introduce non-radiative decay pathways. It is well known that $\mathrm{H}$ has an important role in silicon dangling bonds saturation and in the passivation of grain boundaries. Therefore, for the Er34 sample $(0.03$ at $\%$ of Er, 27.5 at $\% \mathrm{H}, 0$ at $\%)$, the high $\mathrm{H}$ amount can effectively saturate Si dangling bonds (DB) and grain boundaries (GB) so that non-radiative pathway are suppressed yielding a high $\mathrm{Er}^{3+} \mathrm{PL}$ signal (due to the $\mathrm{Er}^{3+}$ ions). Conversely, despite the lower nanocrystals volume fraction pumping the $\mathrm{Er}^{3+} \mathrm{PL}$, the lower $\mathrm{H}$ amount for the Er51 sample (2.3 at\% of Er, 6.7at\% of H) might be responsible of an ineffective passivation of Si DBs and GBs. Since the large amount of Er, DBs and GBs can sink the Er that bond to the Si forming $\mathrm{ErSi}_{2}$, so reducing the number of DB and defects; however, non-radiative pathways still exist lowering the $\mathrm{Er}^{3+} \mathrm{PL}$. However, the lower PL intensity found for the Er40 sample ( $\mu \mathrm{c}-\mathrm{Si}$ in a-Si:H) despite the large hydrogen content indicate that the size of $\mathrm{Si}$ crystallites is crucial for $\mathrm{Er}^{3+}$ sensitizing. Therefore, the analysis of the Er34, Er51 and Er40 samples indicates the main role of nanocrystallites in sensitizing $\mathrm{Er}^{3+}$ and of hydrogen in grain boundaries passivation and, hence, in reduction of non-radiative decay pathways.

When oxygen is present in the silicon matrix, competition exists between silicon and excess of erbium in bonding oxygen forming $\mathrm{SiO}$ and $\mathrm{Er}_{2} \mathrm{O}_{3}$, respectively, independently of the overall $\mathrm{O}$ content. In particular, the analysis of the Er53, and P11 samples show the formation in both samples of $\mathrm{Er}_{2} \mathrm{O}_{3}$ and SiO. However, the comparison of the Er48 and P11 samples indicates that it is not only the overall oxygen content that determines the bonding of the erbium, but the Si matrix nanostructure should also play a role in the bonding configuration of Er. In particular, it is found that excess of Er forms silicide $\mathrm{ErSi}_{2}$ in the Er48 sample, while it forms $\mathrm{Er}_{2} \mathrm{O}_{3}$ in the P11 sample, although Er48 has more oxygen as determined by RBS (see table I). Furthermore, despite the larger crystallite size the PL intensity does not decrease as it happens for the Er40 and P11 samples. This could indicate that there is a role of $\mathrm{ErSi}_{2}$ in substaining the $\mathrm{Er}^{3+} \mathrm{PL}$. The structural differences existing between Er48 and P11 samples are the $\mathrm{SiO}$ stoichiometry of the matrix for Er48, while it is mainly substoichiometric $\mathrm{SiO}_{\mathrm{x}<1}$ for $\mathrm{P} 11$, and the (111) preferential orientation of crystallites in Er48, while they are (200) preferentially oriented in P11 as found by XRD analysis. The SiO stoichiometry for the amorphous matrix and the (111) preferential orientation of large crystallite might be factors promoting bonding of Er to Si at grain boundaries. The different Er bond configuration and PL behavior, let us infer also a possible different site for the Er, being mainly in the amorphous $\mathrm{SiO}$ matrix when it is $\mathrm{Er}_{2} \mathrm{O}_{3}$ (Er53 and P11 samples) and at grain boundaries and/or inside the grain when it is $\mathrm{ErSi}_{2}$ (Er51 and Er48 samples). The different sites for Er might explain the lower PL intensity of the Er53, Er56 and P11 samples (including $\mathrm{Er}_{2} \mathrm{O}_{3}$ 
in the amorphous part), while the higher PL intensity of Er51 and Er48 (including $\mathrm{ErSi}_{2}$ at grain boundaries or within grains) might be due to a more efficient coupling of Er and nanocrystals. Our recent results on different details of the PL feactures at $0.98 \mathrm{eV}$ and $1.18 \mathrm{eV}$, which, however, needs further analysis, seems to support the existence of different sites for Er.

\section{Conclusions}

Er-doped nanocrystalline thin silicon films with different $\mathrm{O} / \mathrm{H}$ ratio, crystallite size and crystalline volume fraction have been prepared by r.f. magnetron sputtering using a target of c-Si and metallic erbium. Their structural, chemical and optical properties were studied. Non-destructive optical characterization of nanostructure has been carried out by spectroscopic ellipsometry and corroborated by Raman spectroscopy. We have studied the dependence of the $\mathrm{Er}^{3+} \mathrm{PL}$ spectra on the nanocrystallinity and $\mathrm{O} / \mathrm{H}$ ratio of the $\mathrm{Si}$ matrix. We observed different intensities of PL peak assigned to the intra-4f transition of $\mathrm{Er}^{3+}$ ion. It is found that the $1.54 \mu \mathrm{m}$ Er-related PL reduces strongly with the increase of silicon crystallite sizes, and for samples with the same crystallite size, the PL intensity increases with the increase of the crystalline fraction. Our results also indicate that samples with high Er content have not Er metallic clusters but $\mathrm{ErSi}_{2}$ or $\mathrm{Er}_{2} \mathrm{O}_{3}$ compounds, and a competition exists between $\mathrm{Si}$ and $\mathrm{Er}$ to get $\mathrm{O}$, yielding $\mathrm{ErSi}_{2}$ or $\mathrm{Er}_{2} \mathrm{O}_{3}$ compounds. A higher $\mathrm{Er}^{3+} \mathrm{PL}$ intensity at $1.54 \mu \mathrm{m}$ is observed for samples including nanocrystallites with a size in the range $1-3 \mathrm{~nm}$ in an a-Si:H matrix. These films can be recognized by SE spectra with a peak at about $3.6 \mathrm{eV}$ and an optical bandgap larger than $2 \mathrm{eV}$. The advantages of the $\mathrm{SE}$ analysis respect to the conventional structural technique are that it is non-destructive, in contrast to HRTEM, and possible crystallization that can be induced during Raman/XRD measurements is avoided.

\section{Acknowledgment}

This work was partially supported by a FCT Project POCTI/CTM/39395/2001 and INTAS Project \#03-51-6486.

\section{References}

[1] - S. Coffa, G. Franzo and F. Priolo, MRS Bulletin, 23 (1998) 25.

[2] - M. Fujii, M. Yoshida, Y. Kanzawa, S. Hayashi, K. Yamamoto, Appl. Phys. Lett., 71 (1997) 1198.

[3] - M. Fujii, M. Yoshida, S. Hayashi, K. Yamamoto, J. Appl. Phys., 84 (1998) 1.

[4] - G. Qin, G.G. Qin, S.H. Wanget., J. Appl. Phys., 85 (1999) 6738. 
[5] - F. Priolo, G. Franzo, F. Iacona, D. Pacifici, V. Vinciguerra, Mat. Sc. Eng. B, 81 (2001) 9.

[6] - P. G. Kik, A. Polman, Mat. Sc. Eng. B, 81 (2001) 3.

[7] - M.F.Cerqueira, J.A.Ferreira, G.J.Adriaenssens, Thin Solid Films 370 (2000) 128.

[8] - I. Campbel and P.M. Fauchet, Solid State Commun., 58 (1986) 739.

[9] - D.A.G. Bruggemann, Ann. Phys. (Leipzig), 24 (1965) 636.

[10] - M. Losurdo, M. M. Giangregorio, P. Capezzuto, G. Bruno, M.F. Cerqueira, E. Alves, M. V. Stepikhova, Appl. Phys. Lett. Vol 82, 16 (2003) 2993.

[11] - G. E. Jellison, M. F. Chisholm, and S. M. Gorbatkin, Appl. Phys. Lett., 62 (1993) 3348.

[12] - D. E. Aspnes and A. A. Studna, Phys. Rev. B, 27 (1983) 985.

[13] - E.D. Palik, Handbook of Optical Constants of Solids II, Academic Press Inc., San Diego, CA, 1991.

[14] - P. Lautenschlager, M. Garriga, L. Vina, M. Cardona, Phys. Rev. B 36, 4821 (1987)

[15] - G. Guizzetti, E. Mazzera, M. Michelini, F. Nava, A. Borghesi, A. Piaggi, J. Appl. Phys. 67, 3393 (1990). 